which it can be treated. With the rapid extension of laboratory tests of great accuracy there is a tendency to rely more and more on laboratory reports and less and less on the examination of the patient, the history of the illness, the family history, the environmental conditions, and the exercise of a wise clinical judgment. In many cases, of course, laboratory findings are required to arrive at correct conclusions, but the student must never be allowed to forget that the most essential consideration in arriving at a correct diagnosis is to study the patient in all his aspects and not to come to conclusions on laboratory tests. The laboratory must serve as a good servant and not be permitted to become the overlord.

As the student advances in his use of observation and deduction great help can be gained through conferences, seminars, clinical lectures, ward rounds, and case presentation by students themselves; these should all be regarded as essential elements of a well-conducted clerkship. Equally essential is it for the student to realize that the knowledge and experience of other professional and technical persons associated in the service of the patient are of great value. Nurses, medical social workers, dietitians, dentists, and others have a contribution to make to the students' better understanding and appreciation of the patient. The clinicopathological conference is the foundation of all educational progress for clinical clerks as well as for interns, residents, and the whole staff: it is at these conferences that the test of good and bad medical practice and teaching can be judged. There is no substitute for it so far as intellectual discipline and stimulus to professional improvements are concerned.

\section{The Aim of Teaching}

The aim of undergraduate medical education is not to provide training in the highly specialized fields of medical and surgical treatment but to give a thorough grounding in the knowledge and synthesis of general medical and surgical diagnosis. Let it be realized that undergraduate medical teaching serves only to lay the foundation for the creation of interest in a subject of ever-increasing complexity and to arouse in the student a psychological curiosity to develop the basic methods and principles that have been ingrained in him.

The successful medical practitioner is a perpetual student, and, in the light of the many developments that are taking place, thanks to the impact of the discoveries of basic sciences on medicine, it can easily be realized that it is not the knowledge of many unrelated facts but the analytical and the progressively expanding mind which will help the student to keep continually in touch with all receptive ideas in the field of science, particularly in its relation to medicine. The chief emphasis, therefore, should be on developing the student's broad understanding, scientific aptitude and approach, powers of accurate reasoning, judgment, resource, initiative, and a determination to put to test the knowledge that has been gained through study and observation.

It is from this point of view that the whole programme of undergraduate medical education should be reviewed. If specialization at the undergraduate level hinders the organization of a unified curriculum, if the curriculum tends to create any rigid barriers between basic medical sciences and the clinical instruction which should follow later, if it does not help to relate the education to the broader culture and science of the times both in the field of preventive medicine and in that of its social implications, then undergraduate medical education will have failed of its purpose. Medical students should be stimulated and inspired by modern concepts of social medicine to realize that they are responsible citizens of the future who should apply their profession, and the knowledge that they have gained, to the besefit of humanity.

\section{An Interesting Period}

One of the most important periods of a medical student's career is the period of internship. He looks forward to this with great interest. The intern is not burdened with a schedule of classes and prospects of formal examination. $\mathrm{He}$ is free from the inhibitions of his undergraduate stage of study, and he has the joy of working with experienced clinicians and seeing how they combine the science and art of medicine in the treatment of their patients. The internship should strengthen and not weaken the student's appreciation of high scientific and ethical standards of practice. In the past, and as it still is in some schools, while the internship was regarded as a part of undergraduate medical education, it was almost entirely concerned with curative medicine. It thus failed in its objective, because internship, properly regulated, should contribute to a better appreciation of the possibilities of preventive and social medicine, and put the intern into closer contact with the life of the patient in respect of environmental conditions, his occupational hazards, and the manner in which he can be rehabilitated. The internship should therefore be utilized as an opportunity of studying community medicine in all its many ramifications through public and private agencies, and should serve as an experience in the practice of preventive as well as curative medicine, in community medicine as well as in hospital and in the out-patient department.

\section{Conclusion}

Thus it will be seen that no part of medical education is so important as that of the undergraduate, and, if the foundations are not well and truly laid, and the broad basis of the objectives of undergraduate medical education not thoroughly appreciated, the role that the future practitioner will be called upon to play will not be fulfilled and the usefulness of the trained doctor will be limited. Medical schools, the teaching profession in the faculties, and all concerned have to realize, therefore, the need for reorientation of the policy of undergraduate medical education, as indeed of all education in the field of medicine.

\section{TECHNIQUES AND METHODS OF MEDICAL EDUCATION}

\author{
BY
}

ALBERTO HURTADo, M.D.

Faculty of Medicine, University of San Marcos, Peru

It is an honour and a privilege, which I greatly appreciate, to preside over one of the sections of the First World Conference on Medical Education. I interpret this high distinction as one of the many indications that the medical profession is really one large institution, without geographical or racial barriers, making a generous effort to achieve a better mental and physical health for mankind. I have not the time to refer specifically to some of the techniques and methods which are actually used in or must be introduced into medical education. The distinguished list of contributors to this section, the variety of subjects to be considered, and the subsequent discussion which they will elicit are indicative that this important phase of medical education will be adequately investigated. It is almost unnecessary to say that our considerations will be closely related to those made in other sections. Methods and techniques are dependent, in part or wholly, on the premedical preparation of the students, the orientation and contents of the medical curriculum, and the new trends in preventive and social medicine. For these reasons it appears to be more pertinent, as a sort of introduction to our work, to comment briefly on the general aspects of the problems we face when we attempt to discuss medical education. 
As a means of emerging from the widespread social unrest and poverty brought about or aggravated by the two great wars which divided the world into bitter factions, and in an effort to prevent the repetition of such catastrophes, international organizations and local governments are giving constantly increasing attention to the improvement of health conditions. It has become an accepted fact that man has the fundamental right to demand adequate protection against the development of disease and the best possible care when he is ill. Hospitals are being built all over the world, and new tendencies, such as socialized medicine, are attempting to solve the problems of preventing and curing illness. But there is little doubt that these efforts, justified as they undoubtedly are, lack in most cases the necessary basic foundation, which is the recognition that a good medical education is an essential factor for the successful accomplishment of health and social programmes. Large sums of money could be saved and a greater benefit obtained if Governments and the public were educated in the belief that a sound training of the men who will be immediately responsible for the effectiveness of such programmes was an essential requisite.

\section{Need for Readjustment}

It is not illogical to affirm that medical education must be regarded as a major health problem of a nation and must have a high priority in its solution. This is especially true in countries where educational standards fall below those considered to be acceptable. It is important to insist on the benefits of employing, as much as possible, local men in carrying out medical work in a given country. However, this major problem is not easy of solution. It has been repeatedly pointed out that medical education is in a transitronal or critical period, and there is universal agreement on the urgent need of readjustment. Unfortunately there is not the same agreement on the way to bring about this readjustment. In reviewing the vast literature on the subject one is impressed with the emphasis with which every writer tries to uphold his personal ideas, and the writers and the ideas may be counted in hundreds and even thousands.

Several factors are apparently responsible for the present situation of uncertainty and confusion. Knowledge and understanding of them are necessary for the adequate evaluation of the methods and techniques which it is convenient to use in teaching medicine. These factors may be separated, from a general point of view, into the quantitative and the qualitative. To the first group belongs the tremendous advance in the knowledge related to the so-called basic sciences or preclinical courses. Some of these, such as anatomy, chemistry, physiology, bacteriology, and pharmacology, have long been accepted as part of the medical curriculum, and others, such as mathematics and physics, especially the latter, have given enough proof of their right to be included, at least up to certain degree, in such a group. In the clinical courses are included the great body of information which must be given to the students concerning the new concepts in psychiatry and social and preventive medicine; care of man when exposed to warfare; use of new therapeutic agents, including antibiotics, vitamins, and hormones, and the new surgical and medical procedures developed for the restoration of health.

From a qualitative point of view we have the close approach of preclinical to clinical courses; the interpretation of symptoms, signs, treatment, and prognosis in physiomorphological terms, which introduces a dynamic rather than a static estimation of illness and its effects; the rapid development of an integrated concept in the consideration of the healthy and sick human body and mind, a concept which threatens to abolish the barriers between the classical departments and the time-honoured sequence in the curri- culum; and, finally, the acceptance of the importance of considering the patient not as an isolated individual but as part of the family and society, from the points of view of both the consequences and the clinical peculiarities of the disease.

\section{A Complicated Task}

Thus the teacher of medicine faces to-day an extremely complicated task. He has to give to the student a constantly increasing factual knowledge within a period of time which has not changed for decades. One method followed is the elimination of certain facts in favour of others, either new or considered more important, within the general orientation that medical education cannot pretend to impart anything but the most essential material, leaving for the postgraduate period the acquisition of further knowledge, especially in what concerns the practical application of general principles. It is evident that this method of solution cannot go on indefinitely. It is based, in part at least, on a false premise, because it implies that new facts mean necessarily the elimination of previous ones. This is not always the case. Knowledge does not advance only by replacement ; often it does so by addition. At the rate of our present advance in medical sciences it will occur, rather sooner than later, that the medical student leaves the school with only an elementary vision of what is necessary for him to know. Most medical educators are reluctant to consider a lengthening of undergraduate education. On the other hand, premedical training and postgraduate instruction have in recent years received a more liberal extension. One cannot escape the thought that the same consideration will probably have to be applied to undergraduate medical education, especially in those countries in which it is carried out in only four years.

\section{Habits of Thinking and Reasoning}

But the problems to be solved do not relate only to factual knowledge. Frequently, and with ample justification, it is indicated that the medical student must be taught the habits of thinking and reasoning, and the ability to discriminate on the relative value of the numerous contributions which are constantly being made to our knowledge. Some writers have extensively discussed the relative importance of these two aspects of medical education : learning facts and learning to think. Each has been given priority over the other. We must accept, however, that both are important, intimately connected, and dependent on each other. One cannot think and reason well if an appropriate body of knowledge does not back these intellectual functions.

The complexity of medical education is increased by the fact that its objective is not only the training of practitioners, either general or specialized. The medical school is the proper place for the selection and preparation of future teachers and investigators. This role is vital for the continuation of progress, for the necessary renewal of teaching personnel, and for the fulfilment of one of the most basic functions of a university, which is the undertaking of research. Everybody agrees that research gives to the teacher a greater authority and a better framework of mind for his thinking and makes him a greater inspiration to his students. But there is no uniformity of opinion concerning several points. How soon should the selected student be attracted to research? Is a limited investigative activity desirable in the curriculum? Is it convenient for the future teacher or investigator to enter early in the field of his choice, or is it better for him to acquire previously a general experience? What methods should be used to evaluate the future qualities of students? These and many other questions demand a closer study.

\section{Conclusion}

Medical education presents problems such as those briefly mentioned, which may be considered to be universal in character, which can be formulated in general terms, and which are apt to be applied wherever medical training is 
carried out. But local conditions may complicate in a varying degree the solution of these problems. In most countries of Latin America, and possibly in some other regions of the world, an excess of students and economical factors complicate the picture. An erroneous concept of democracy has frequently opened the medical schools to all those who merely wish to pursue a medical education. The result has been the admittance of a number of students entirely incompatible with a high efficiency in the training, and this situation has brought about all the evils of mass education, in which the personal and highly useful contact between the teacher and the student is practically suppressed. The limitation of funds available for teaching and research makes difficult the introduction of the necessary reforms and the proper use of men adequately trained. In addition, geographical and social conditions are still responsible for large areas of inadequate medical and sanitary attention, which results in an uneven distribution of the graduates, who seek the large populated centres in which they find a better scientific environment for their professional activities.

Fortunately, facing these handicaps there is, in the medical school authorities and members, and in the medical profession in general, a sincere desire and a determined intention to raise the educational standards to the level found in those countries which have marked out the pathways in this field. These sentiments explain the presence in this meeting of men who have come from our distant continent. Allow me to conclude by expressing my confidence in the ultimate result of these deliberations, and my best wishes, participated in. I am sure, by all of you, for the success of this conference, which represents a united effort to raise the educational standards of our profession.

\section{PREVENTIVE AND SOCIAL MEDICINE*}

$$
\begin{gathered}
\text { BY } \\
\text { RENE SAND, M.D. } \\
\text { Emeritus Professor of Social Medicine, University of } \\
\text { Brussels }
\end{gathered}
$$

In the hospital as well as in private practice the physician deals essentially with sick people, so that the codes of ethics drawn up by the medical profession in the various countries define the doctor's duties towards his patient, not in a more general sense towards the person who consults him in health or disease. So had Hippocrates in the Oath, although elsewhere in his work he maintains that the first duty of the physician is to protect and cultivate health.

When, about a century ago, sanitation was revived and put mainly in the hands of the engineer, and when medical health officers were appointed, the doctor still served the cause of health by giving advice as family physician. Unfortunately, the advent of specialization has nowadays reduced the part played by the general practitioner.

Preventive medicine in the strict sense of the termthat is, preventive medical procedures-appeared with Jenner and his first immunization, followed a century later by the preventive examinations of pregnant women, infants, and school-children. Occupational medicine was launched by Ramazzini in 1700, medico-social surveys and statistics by Villermé in 1828.

In the century and a quarter which has elapsed since these pioneer days, preventive and social medicine-the terms are often used as synonyms for reasons of con-

*This paper was received for publication just before Professor Sand underwent an operation which prevented him from coming to London as one of the Vice-Presidents of the First World Conference on Medical Education. The news of his death was received as this issue of the Journal went to press. venience-have proved their case, and if weighed against curative medicine would no doubt be found more effective and less costly. However, they occupy only a small place in medical teaching; and they come late in the curriculum, at a time when the student's mind is already monopolized by the clinical and laboratory aspects of disease. Besides, having had no instruction in the social sciences, he feels lost in a strange country.

\section{Signs of Improvement}

Here, as in so many other fields, institutions have lagged behind needs. Hospital and medical practice are still turned mainly towards cure. The Faculty is still made up of a large group of clinicians, a large group of laboratory workers, and a solitary professor of public health. Yet signs of change are appearing. The importance given to preventive medicine by the Report of the B.M.A. (The Training of a Doctor), and by the Goodenough Report, as well as by similar documents elsewhere; the creation of departments, institutes, and chairs of preventive and social medicine in various countries; the part assigned to these disciplines by W.H.O. and other international organizations -all point in the same direction.

If the social elements in many medical schools are still comparatively neglected it is because the training takes place in the hospital, from which these elements are absent, and because few members of the Faculty have studied social sciences and acquired experience in social work. However, a growing number of hospitals have almoners, and use them to demonstrate the circumstances and needs of the patients. Besides, the idea is spreading that a much greater part of the training should be given in the out-patient department and in the home itself, either by associating the students with the daily work of general practitioners, as Professor Crew does in Edinburgh, or by sending the students to observe domiciliary cases.

\section{Need for Change}

The lack of training in the social sciences calls for a radical change : in his first university year the student is taught mathematics, physics, chemistry, and biology, which are required for the understanding of health and disease; he should study also psychology and sociology, not only because he will need this initiation to play his full part as a doctor but because everyone, and more especially a university graduate, should understand himself and the world in which he lives. Biology teaches us to understand our body; psychology to understand our mind and our behaviour; sociology to understand the structure and life of the groups, small and large, of which we are members. So long as psychology and sociology remained mainly speculative their practical use was limited. More realistic to-day, they have become indispensable to the statesman, the employer, and the parent, to the judge, the Army officer, and the doctor.

On the background of biology, psychology, and sociology, acquired in the first year, the principles of preventive and social medicine should be taught at the same time as the basic sciences, anatomy, and physiology. The aim of medicine should be defined as the maintenance and culture of physical, mental, and social health, with the repair of damaged health as the second consideration only. The nation-wide and permanent achievements of preventive medicine and public health should be put in parallel with the remarkable but individual and temporary successes of curative medicine.

Later, when the student enters the hospital, the part played by social, economic, and occupational factors should be explained by the internist, the surgeon, the obstetrician, the paediatrician, the psychiatrist, with the help of the almoner, and preferably also of the professor of preventive or social medicine; and this teaching should take place in the clinical lessons, in the daily rounds of the wards, in the out-patient department, in the dispensaries and clinics, and in the home itself. 